\section{The Transmutation of Disability to Disease: The Ethics of Autism Research}

\author{
PALOMA OROZCO SCOTT, MA (D)
}

*Author affiliations can be found in the back matter of this article
PUBLISHED ABSTRACT

\title{
ABSTRACT
}

This paper will look at the ethics of research and treatment of autism, and how history and disability justice movements may inform our ethical stance as physicians. For this paper I will use autistics to refer to people with autism as this is the preferred language from those in the disability movement I will be citing. The central question, which may never be answered, is how can physicians ethically wield the power of pathologization in a society with rapidly advancing assistive technologies that throw into question what is and is not disability. Central to this presentation with be Georges Canguilhem's writing in On The Normal and The Pathological, specifically his assertion that "health is life in the silence of the organs." What does it mean when the organs, understood broadly as the body, "speak" to the individual but their presence as difference and even as disability does not translate to the patient as disease?

The specific case I will look at is the engineering and testing of oxytocin nasal sprays on young children with autism (Kong, Lu 2020). Literature already exists critiquing medical institutions and health practitioners use of Applied Behavior Analysis (ABA) in the "treatment" of autism, as this form of therapy can be experienced by the participant as coercive, traumatic, and even violent (Yergeau 2018). Where this paper adds to the discussion is to further question the ethics of autism research even in cases where the proposed intervention, oxytocin nasal spray, poses minimal physical harm to the child. In medical ethics, is there a place for the historical abuses of autistics to inform our current practices? And furthermore is it the person/patient or the doctor who interpolates the person into the role of the patient?

I will briefly engage with the debate concerning the dichotomization of the social and the medical model, critiqued by sociologist Tom Shakespeare, only insomuch as this paper is not arguing about the validity of those models but about how the medical model comes to be invoked and how the "patient" is produced.
CORRESPONDING AUTHOR:

\section{Paloma Orozco Scott, MA}

Icahn School of Medicine at Mount Sinai, US

paloma.orozcoscott@icahn. mssm.edu

KEYWORDS:

Disability Justice; Medical Ethics; Pathologization; Autism

TO CITE THIS ARTICLE: Orozco Scott P. The Transmutation of Disability to Disease: The Ethics of Autism Research. ISMMS Journal of Science and Medicine. 2021; 1(1): 14, pp. 1-2. DOI: https:// doi.org/10.29024/ijsm.40 
The author has no competing interests to declare.

ISMMS Journal of Science

and Medicine

DOI: $10.29024 /$ ijsm. 40

\section{AUTHOR AFFILIATION}

Paloma Orozco Scott, MA (D) orcid.org/0000-0003-1261-7748

Icahn School of Medicine at Mount Sinai, US

TO CITE THIS ARTICLE:

Orozco Scott P. The

Transmutation of Disability to

Disease: The Ethics of Autism

Research. ISMMS Journal of

Science and Medicine. 2021;

1(1): 14, pp. 1-2. DOI: https://

doi.org/10.29024/ijsm.40

Submitted: 21 December 2020

Accepted: 21 December 2020

Published: 27 January 2021

\section{COPYRIGHT:}

(c) 2021 The Author(s). This is an open-access article distributed under the terms of the Creative Commons Attribution 4.0 International License (CC-BY 4.0), which permits unrestricted use, distribution, and reproduction in any medium, provided the original author and source are credited. See http://creativecommons.org/ licenses/by/4.0/.

ISMMS Journal of Science and Medicine is a peer-reviewed 